\title{
USO DE COMPÓSITOS EM REPAROS NA INDÚSTRIA NAVAL E OFFSHORE
}

\section{ARTIGO DE REVISÃO}

ALVES, Rafael da Silva ${ }^{1}$

AROUCHE, Marcio Moreira ${ }^{2}$

ALVES, Rafael da Silva. AROUCHE, Marcio Moreira. Uso de compósitos em reparos na indústria naval e offshore. Revista Científica Multidisciplinar Núcleo do Conhecimento. Ano 05, Ed. 05, Vol. 07, pp. 62-81. Maio de 2020. ISSN: 2448-0959, Link de acesso: https://www.nucleodoconhecimento.com.br/engenhariamecanica/industria-naval

\section{RESUMO}

O uso de compósitos já vem sendo feito há anos na indústria aeroespacial, em pequenas embarcações e em componentes da indústria naval. Mais recentemente, a indústria naval e offshore compreendeu a sua importância e utilização, sobretudo como uma ferramenta indispensável de reparo para estruturas fissuradas e tubulações danificadas por corrosão. Esse artigo de revisão sintetiza e apresenta os métodos e suas aplicações de reparos com compósitos dentro da indústria naval e offshore. O trabalho apresenta o resultado de diversos estudos que foram feitos nessa área, ou seja, sobre os principais tipos de reparo com compósitos. A revisão da literatura indica que o desenvolvimento dessa tecnologia avança muito rápido e se torna cada vez mais utilizada em diversas aplicações.

Palavras-chave: Defeito em estruturas metálicas, reparo com compósito, juntas coladas, CFRP, GFRP.

\footnotetext{
${ }^{1}$ Engenheiro Naval, Graduado pela UFRJ.

2 Engenheiro Mecânico e Mestre pelo CEFET/RJ.
} 


\section{INTRODUÇÃO}

Os materiais compósitos apareceram no mercado para suprir necessidades dos mais diferentes segmentos da indústria, tendo a finalidade de se obter determinado benefícios em relação aos ditos materiais de engenharia convencionais. Eles possuem vantagens como facilidade de processamento e combinação de propriedades, seja pela variação da quantidade de cada componente, da forma geométrica ou do tipo de cada componente. Além de aliar a alta resistência mecânica com boa ductilidade, esses materiais possibilitam que o produto possua uma melhor estabilidade dimensional e resistência mecânica, e, em alguns casos, maior tenacidade (FREIRE; MONTEIRO; CYRINO, 2013). As propriedades mecânicas dos materiais compósitos dependem das propriedades dos seus componentes, da aderência entre a fibra e a superfície e da transferência de carga da superfície para as fibras. Todos esses fatores são influenciados por agentes externos, como a umidade (FUJIYAMA; BASTIAN, 2007).

O uso de materiais compósitos vem crescendo significativamente, sobretudo na indústria naval e offshore, tendo, como objetivo, a redução do peso de estruturas pesadas, mas ainda não suporta condições ambientais adversas. As fibras reforçadas com polímeros (Fibre-reinforced polymers FRP) são mais comumente usadas em razão da relação de força-peso. Essa tecnologia foi desenvolvida na indústria aeroespacial e foi levada à todas as áreas (AROUCHE et al, 2019). Atualmente, materiais compósitos são amplamente usados para reparos de componentes metálicos na indústria de óleo e gás, offshore e onshore. A ligação adesiva é a tecnologia mais eficiente em termos de peso e performance para juntar esses dois materiais. Dessa forma, as juntas coladas de compósito e metal são práticas comuns à indústria naval.

O processo de colagem entre materiais distintos e o seus efeitos na resistência da junta têm sido investigados por diversos pesquisadores que encontraram uma influência positiva da colagem multi-material em aplicações estruturais (AROUCHE et al, 2018). Muitas tecnologias têm sido desenvolvidas e muitas pesquisas têm sido feitas nesse campo, mas ainda é necessário entender melhor como aplicar essa 
solução para cada tipo de projeto, a fim de obter a melhor resposta para cada singularidade. Há muito a ser explorado, e, também, conhecido, principalmente tratando-se da ação de tecnologias à longo prazo em ambientes adversos. Esse trabalho tem como objetivo apresentar e descrever os métodos e técnicas empregados nos reparos com compósitos em estruturas metálicas usados na indústria naval e offshore. Serão abordadas as pesquisas e os resultados encontrados em relação ao uso dessa tecnologia ao longo do tempo, tendo em vista que essa é uma tecnologia nova.

\section{METODOLOGIA}

Para a realização desse trabalho foi feita uma busca sistemática de artigos científicos, usando a base de dados eletrônicos CAPES periódicos, Google acadêmico, Compendex (Engineers Village). Encontrou-se, nessa coleta, além de artigos, outras publicações cientificas, teses e livros relacionados ao tema. Foram utilizadas as regras SSC, "Review of current pratices of fracture repair procedures for ship structures" e DNV "Design, fabrication, operation and, qualification of bonded repair of steel structures". Os descritores utilizados foram "Adhesively bonded joints", "composite repair", "bond repair", "defects in metal structures", "metallic naval structures", "cold repair", "welding" e "non-welding". Como critérios para inclusão de artigos foram adotados: artigos publicados em revistas e jornais de engenharia, entre os anos de 1994 e 2020, na língua inglesa e portuguesa.

\section{FUNDAMENTAÇÃO TEÓRICA}

\subsection{REPAROS COM COMPÓSITOS}

O compósito ou material compósito se caracteriza por duas ou mais fases, essas sendo de diferentes propriedades físicas e químicas. Os compósitos utilizados mais comumente são aqueles que utilizam fibras de carbono e de vidro como reforço e são referidos pelas siglas GFRP (Glass Fiber reinforced Polymers) e CFRP (Carbon Fiber Reinforced Polymers). Esses materiais, por um grande período, foram apenas utilizados em estruturas não críticas de navios e em pequenas embarcações. $O$ 
panorama de seu uso, atualmente, mudou e os compósitos são aplicados em diferentes finalidades em estruturas navais (MOURITZ et al, 2001). No Brasil, como no mundo todo, essa tecnologia tem sido cada vez mais utilizada.

Entretanto, à longo prazo, pouco é conhecido sobre sua performance quando utilizado em estruturas navais em operação, as quais possuem aplicações dinâmicas e severas (MENICONI; LANA; MORIKAWA, 2014). A parte danificada de uma unidade flutuante offshore, seja tubulação, tanque de lastro, casco ou qualquer outra, geralmente, é reparada com solda. Todavia, esse não é o tipo de procedimento ideal para unidades offshore porque demanda o desligamento da planta e implica em uma grande perda econômica e de atraso na produção (BARROS et al, 2017). Para reparar painéis danificados, uma alternativa aos métodos convencionais de manutenção é o reparo com compósitos.

O método de reparo com compósito é feito com a sua laminação em uma área danificada para reparar a estrutura, fazendo com que as tensões em torno do defeito sejam transferidas e impedindo o seu crescimento. O reparo pode ser feito "in situ" sem demandar o uso de trabalho à quente, e, assim sendo, elimina-se o risco de explosão. Na indústria de petróleo e gás, esse método pode ser especialmente favorável, visto que, como se trata de um processo de união à frio, pode reduzir o impacto do trabalho de manutenção ou modificações devido à redução do perigo de explosões (ECHTERMEYER et al, 2014). Esses reparos também podem ser utilizados como solução temporária até que a manutenção programada seja executada. $\mathrm{O}$ princípio do reparo com compósito é mostrado na figura 1. 
Figura 1 - Reparo com compósito

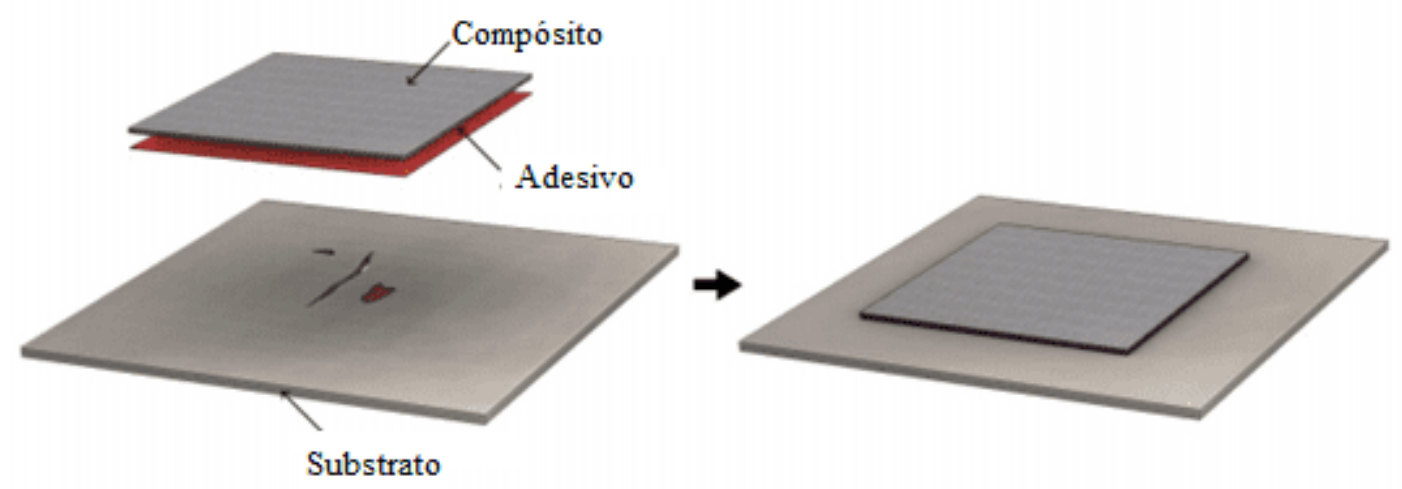

Fonte: Autor (adaptado de Alves, 2018)

Segundo a D. N. V (2015), na realização do reparo com compósito, a primeira tarefa é a preparação da superfície, não importando qual a técnica de fabricação do compósito esteja sendo empregada. A preparação serve para produzir rugosidade superficial e limpeza da superfície. A rugosidade é obtida por esmeril ou jateamento, entretanto, cada método proporciona um diferente resultado que deve ser levado em conta no projeto. A seguir, caso o reparo seja feito em fibra de carbono, é depositada uma camada de fibra de vidro para separar a fibra de carbono da superfície do metal, evitando, assim, a corrosão galvânica. Dessa forma, pode ser colocado o restante da fibra e essa pode ser em forma de pré-impregnação ou fibras secas, caso a infusão de resina seja usada. O calor pode ser aplicado quando a infusão ou consolidação estiver completa, se necessário, para o adesivo curar. Os reparos com compósitos são usados nas seguintes situações:

- Vedação de vazamento;

- Reforço da estrutura, devido à carga adicional ou contra explosões.

- Reparação de fissuras por fadiga;

- Reparação de danos por corrosão; 
O reparo com compósito apresenta algumas vantagens quando comparado ao reparo convencional. As vantagens do reparo com compósito em detrimento do reparo tradicional são:

- Fornece uma interface de vedação;

- Pode ser executado em uma superfície de geometria complexa;

- Não há necessidade de remoção dos compartimentos vizinhos para realização;

- Rápida aplicação;

- Reduz os custos de manutenção;

- Materiais fáceis de transportar, leves e manusear no local de trabalho.

Os métodos mais comuns utilizados nesse tipo de reparo são: pré-impregnadas, laminação manual e infusão de resina. Os pontos positivos e negativos de cada método para aplicar um reparo com compósito são:

1. Pré-impregnadas:

Vantagens:

- O de baixa temperatura de cura é curado à temperatura ambiente;

- Não é necessária nenhuma mistura de resina no local;

- Baixa emissão volátil;

- As camadas de reparo se aderem umas às outras e às superfícies verticais;

- Não há chance de reparos secos, tendo em vista que as fibras já estão infundidas.

Desvantagens:

- O armazenamento e o transporte no local de trabalho podem ser difíceis, o préimpregnado fora do resfriamento tem vida útil limitada (apenas seis dias para a cura de baixa temperatura);

- É necessária uma maior temperatura para o processamento;

- Vazios entre as camadas podem ocorrer;

- Custo do material e dos consumíveis maior; 
- Exigido trabalhador um maior nível de habilidade;

2. Laminação manual:

Vantagens:

- Cobertor aquecedor, armadilha de resina e saco de vácuo não são necessários;

- Custo menor de material e dos consumíveis;

- Operador com nível inferior de habilidade requerida se comparado aos outros métodos;

- Camadas de reparo fáceis de aplicar em superfícies verticais;

- Onde o saco de vácuo não é prático, por exemplo, onde os cabos passam por buracos no local a ser reparado, pode ser usado.

Desvantagens:

- Altas emissões voláteis;

- A qualidade é levemente inferior aos outros métodos;

- Devido à necessidade de a resina ser feita no local, erros podem ocorrer;

3. Infusão de resina:

Vantagens:

- Mais indicada para grandes reparos;

- Qualidade superior à laminação manual;

- Baixas emissões voláteis.

Desvantagens:

- Exige um maior nível de habilidade do trabalhador;

- Material de menor custo, porém consumíveis mais caros;

- Devido à necessidade da mistura da resina ser feita no local, erros podem ocorrer;

- Para aplicar a infusão de resina no local, é necessário secar a área; 
- Pelas fibras serem secas, elas não aderem às superfícies verticais.

\subsection{MATERIAIS}

No desenvolvimento de um projeto de reparo com compósitos, o material do substrato e as propriedades do material compósito têm que atender às características mínimas de estresse, isto é, a tensão do aço tem que ser usada em acordo de um código aplicável, de maneira que o carregamento de escoamento da estrutura danificada deve ser conhecido, e, desse modo, encontra-se os valores certos das tensões. Como padrão, o módulo de Young do substrato de aço deve ser considerado em GPa. Quanto ao adesivo a ser utilizado no reparo, esse pode ser o mesmo do material da matriz, que serve, também, para formar a ligação com o substrato ou um adesivo especifico para o reparo à frio. $O$ quão bem esse adesivo vai se unir a substrato está ligado a vários fatores, dentre eles:

- Orientação da carga;

- Tenacidade à ruptura e resistência de colagem;

- Preparo do substrato e condições da superfície;

- Quantidade vazia paro o adesivo preencher.

Todos os fatores supracitados precisam de controle durante o processo de produção e são controlados a partir de soluções dadas no projeto. Em uma análise, devem ser confirmadas todas as propriedades relevantes por meio de valores experimentais de modelos com linha adesiva e propriedades aderentes representativas. No que tange o longo prazo, as propriedades que são mais sensíveis, no caso dos adesivos, são a perda das propriedades adesivas e o comportamento em fadiga da linha adesiva. É preciso combinar matérias com boa durabilidade para o ambiente e tipo de operação que será aplicado, e, para tal, é recomendado testes de triagem para a identificação da melhor combinação de materiais. Finalmente, é preciso que os materiais compósitos possuam algumas características para que sejam empregados em reparos. 
As resinas mais utilizadas são as termofixas, tendo em vista que são semelhantes ou compatíveis com os adesivos, o que permite a ligação entre o substrato e o laminado. A medida certa dos materiais se dá em função das exigências de rigidez e resistência necessárias no reparo final, bem como o ambiente de operação, tipo de fabricação e condições sob as quais o reparo será feito. Para grande parte dos reparos colados que irão fazer parte de uma parte da estrutura como o casco, os requisitos para rigidez e força exigirão o uso de fibra de carbono ou equivalentes, pois essas possuem a característica de alta rigidez e força. Para evitar problemas com corrosão galvânica, todo projeto de reparo adesivo que utiliza fibras que são condutivas, como, por exemplo, a fibra de carbono, devem ser separadas do substrato. No caso de reparos pré-fabricados, essa separação pode ser feita controlando a espessura da linha de adesão.

Já para os reparos que são laminados direto no substrato devem ser usadas uma ou mais camadas de fibra de vidro, de modo a isolar o reparo do substrato e evitar a corrosão do mesmo. Por último, o material da matriz ou resina deve ser termo endurecível ou termoplástico. Os termoplásticos oferecem uma maior resistência ao ambiente, mas, por vezes, mostram-se problemáticos em sua ligação ao substrato de aço. Por isso, certos materiais matriciais termoplásticos precisam que na superfície seja realizada uma preparação especializada para obtenção de uma adesão adequada. Todavia, os termo endurecíveis possuem propriedades de ligação melhores, porque são quimicamente iguais ou compatíveis com o material adesivo. Os materiais termo endurecíveis podem ser vinilésteres, polialiléster, epóxis ou resinas mais especificas, como os uretanos que oferecem diferenças na cura ou processamento. Esses podem curar mesmo expostos à água.

\section{REPARO DE TRINCAS EM ESTRUTURAS DE AÇO}

O objetivo do reparo com compósitos é impedir a progressão da trinca. Eles agem retirando a tensão presente na trinca e interrompem o crescimento da mesma na área danificada. Uma limpeza da região danificada é feita para evitar contaminação do reparo, depois uma camada de resina é aplicada para servir como adesivo entre o compósito e o substrato. Então uma camada com fibra de vidro, que serve para o 
isolamento, é aplicada impedindo a corrosão, seguida pelo processo de laminação de fibra de carbono que dá resistência ao reparo (MENICONI; LANA; MORIKAWA, 2014). A figura 2 ilustra o processo

Figura 2 - Esquematização de reparo com compósito em trinca
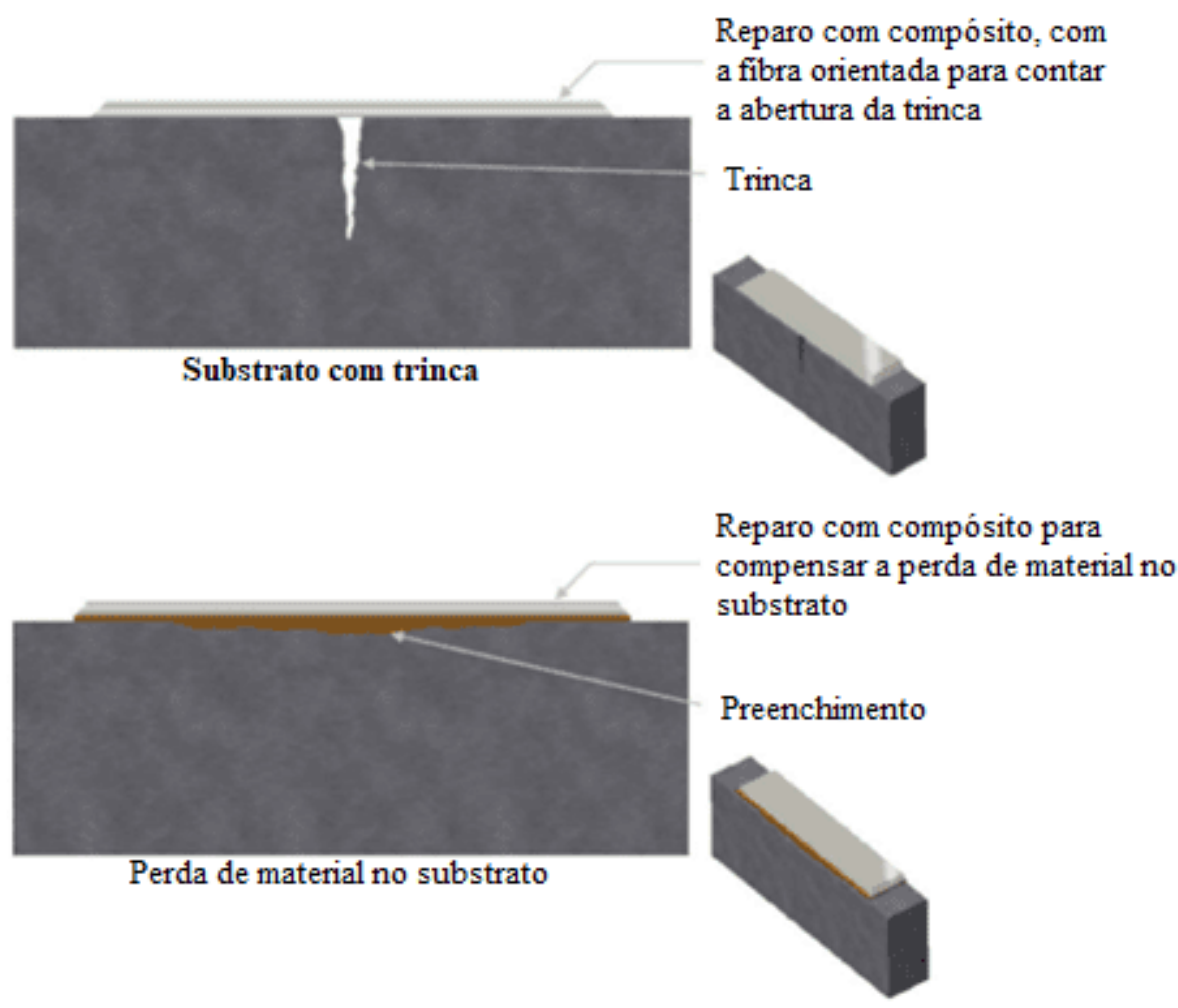

Fonte: DNV (2015)

\subsection{REPARO DE CORROSÃO EM TUBOS}

A corrosão gera danos aos tubos pois retira sua integridade estrutural, provocando vazamentos ou perda de pressão. O processo de reparos em tubos é semelhante ao processo de reparo quando realizado em uma trinca. Uma limpeza da região danificada é feita para evitar contaminação do reparo, depois uma camada de resina é aplicada para servir como adesivo entre o compósito e o substrato. Finalmente, camadas de fibra de vidro são laminadas, sendo a fibra de vidro a mais utilizada nesse tipo de reparo porque não requer muita resistência mecânica (BARROS et al, 2017). O processo é mostrado nas figuras 3 e 4 . 
Figura 3 - Esquema de reparo em tubulações

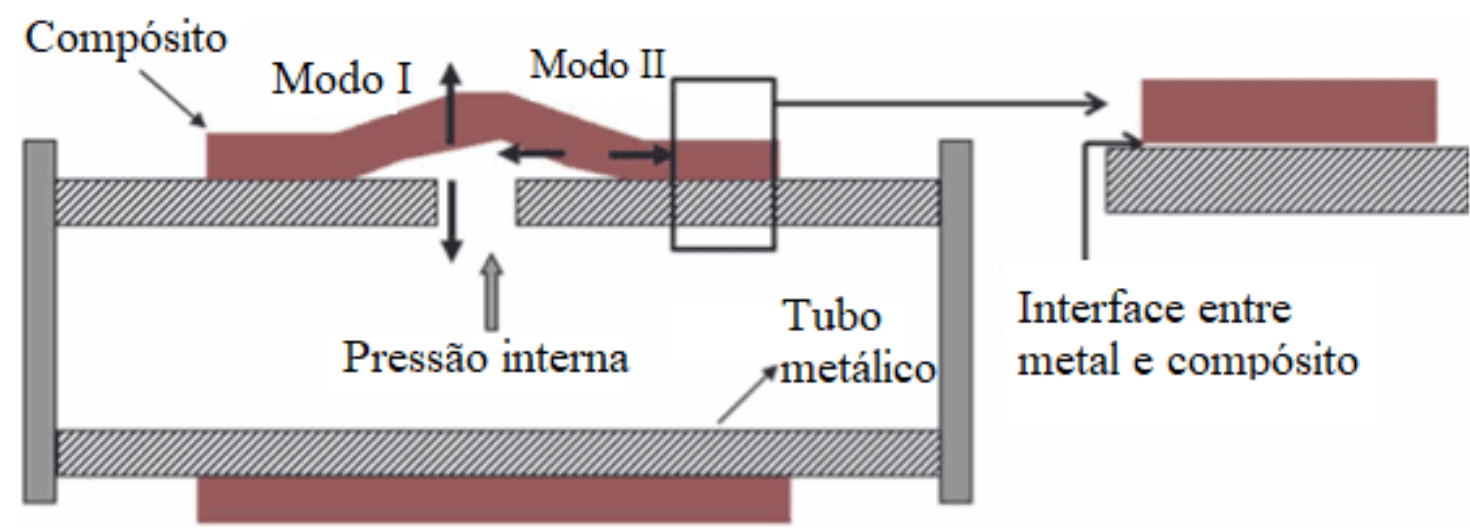

Fonte: Barros et al (2017)

Figura 4 - Laminação de reparo em tubulações

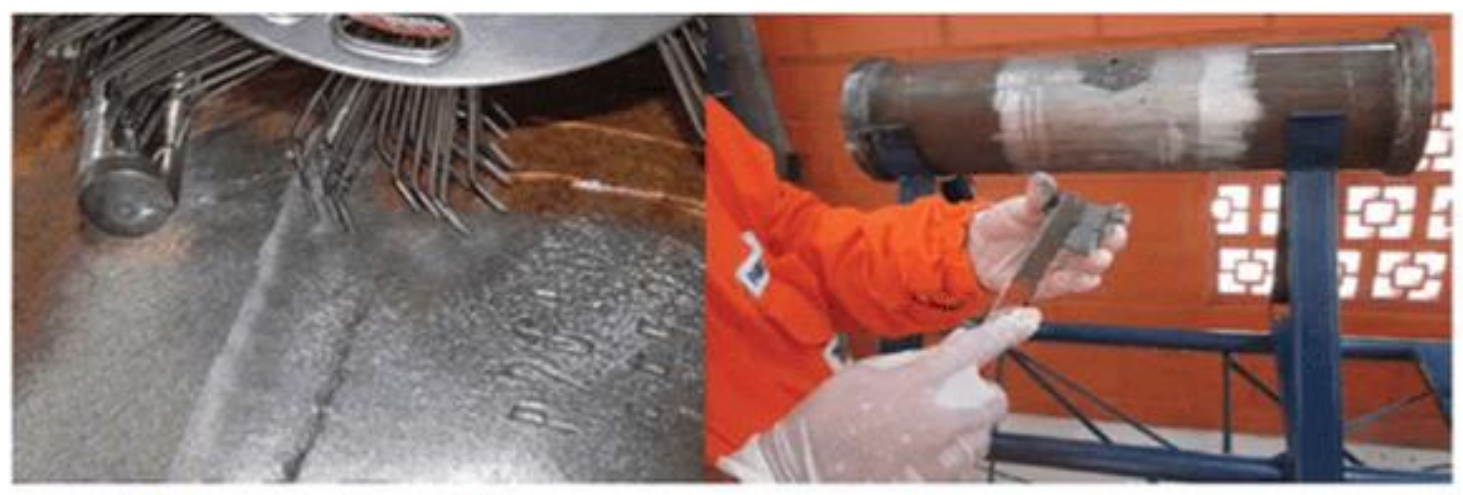

(a) Preparação da superficie

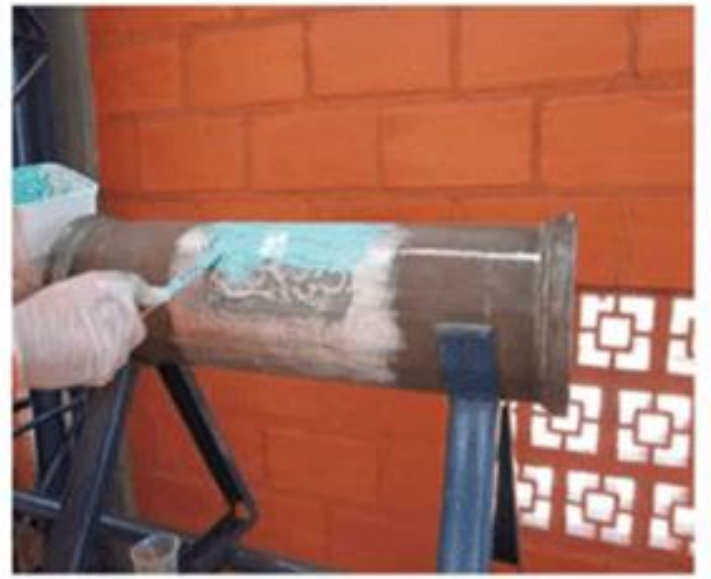

(c) Aplicando resina epoxi na superficie tratada (b) Limpeza da superficie

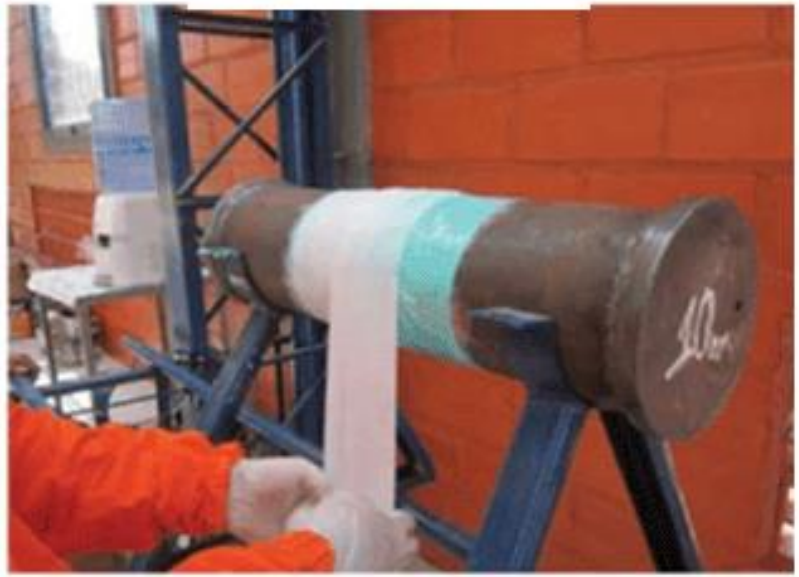

(d) Envólucro de fibra de vidro

Fonte: Barros et al (2017) 


\section{REPAROS DE TRINCAS EM ESTRUTURAS DE ALUMÍNIO}

Em estruturas de alumínio o processo de reparo de trincas se assemelha ao processo de reparos de trincas em estruturas de aço. Porém, se diferencia por uma camada de fibra de vidro ser usada no exterior para proteger o reparo. Assim como no reparo em estrutura de aço, é aplicada uma camada de resina que serve como adesivo, sendo está isolante ou não e da mesma forma que no reparo em estrutura de aço se a resina não for isolante é aplicada então uma camada de fibra de vidro, para agir como isolante. E então depois são laminadas camadas que atendam o reparo em questão de fibra de carbono, por último uma camada de fibra de vidro é laminada sobre o reparo para proteger do ambiente (GRABOVAC; WHITTAKER, 2009). O processo é ilustrado nas figuras 5 e 6 .

Figura 5 - Estrutura de alumínio reparada com compósito

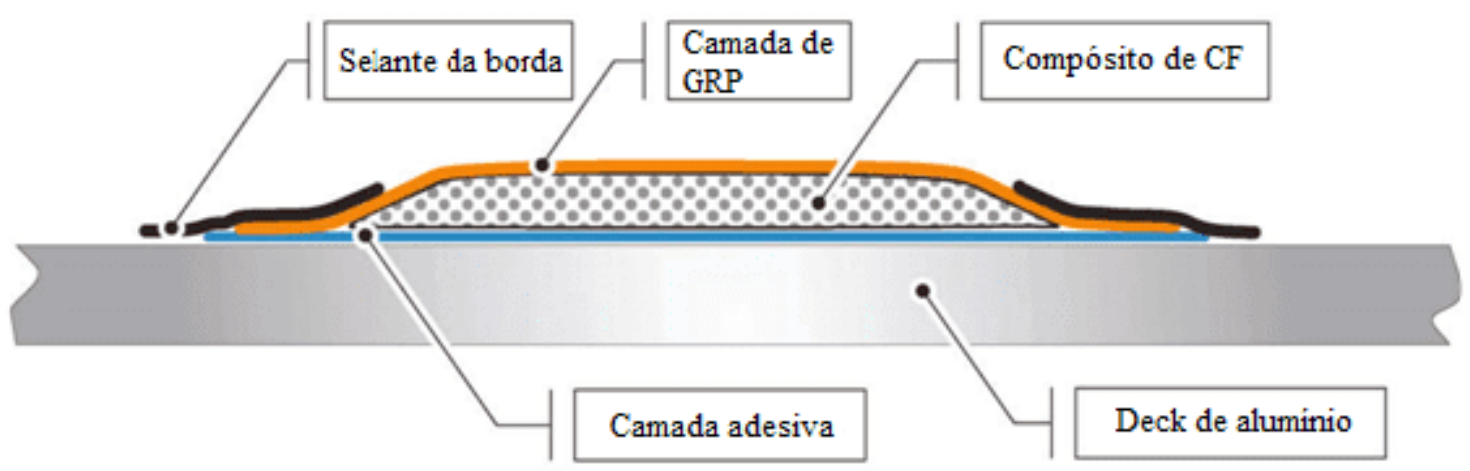

Fonte: Grabovac e Whittaker (2009) 
Figura 6 - Convés de alumínio de uma embarcação sendo reparado com compósito

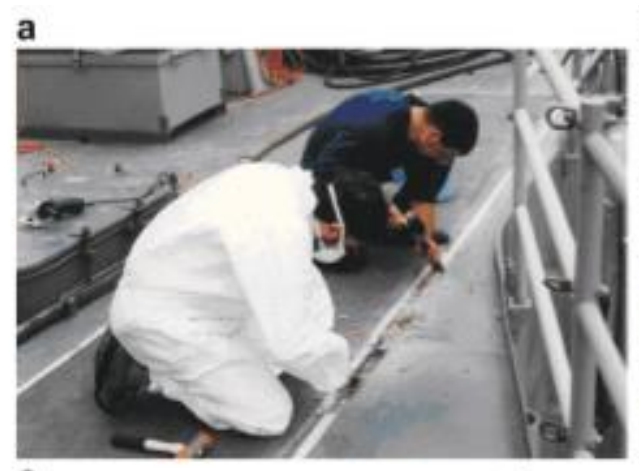

b

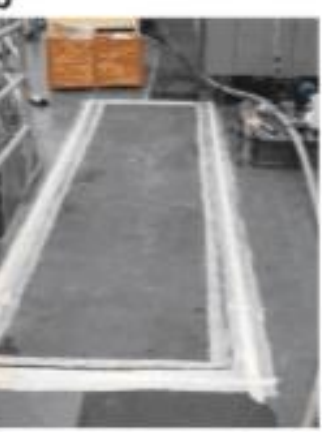

C

d
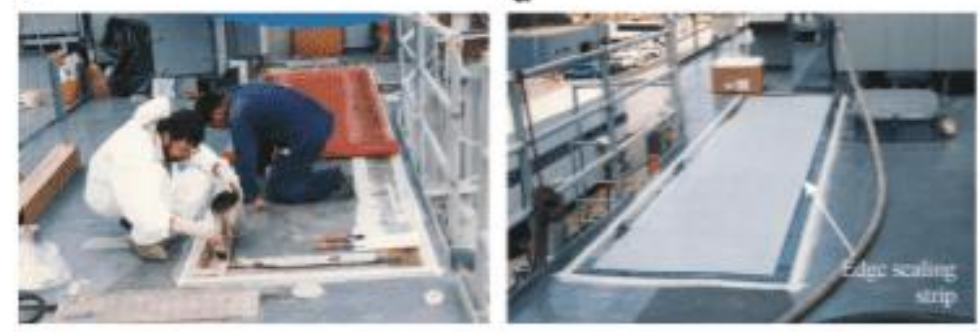

Fonte: Grabovac e Whittaker (2009)

\subsection{COBERTURA (COATING)}

A cobertura ou coating é um processo de aplicação de uma camada de resina misturada com outro material que tem a função de dar proteção contra o ambiente, impedindo, assim, problemas de corrosão e erosão, como é mostrado na figura 7 . Nesse tipo de reparo não fica caracterizada a reparação de rigidez mecânica da peça. 
Figura 7 - Aplicação de cobertura ou coating

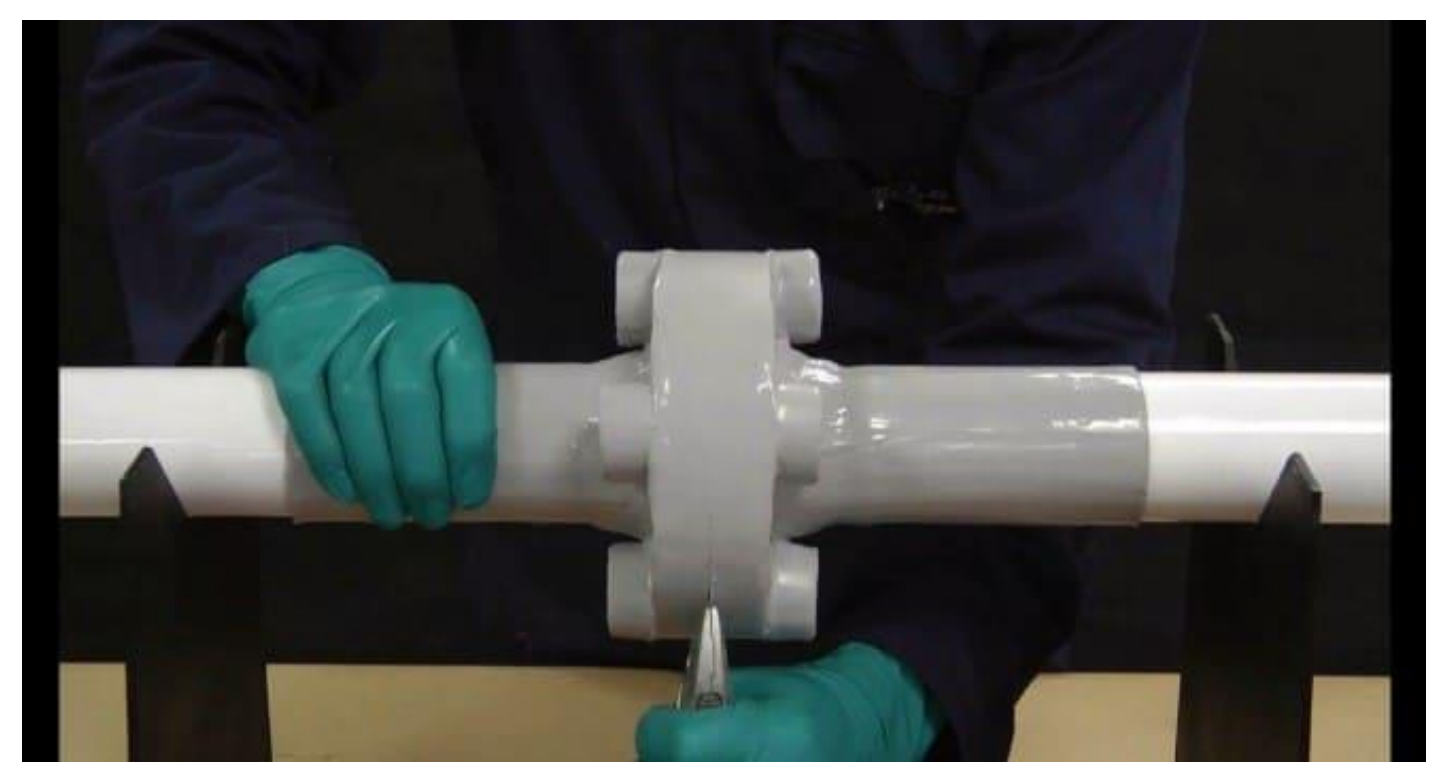

Fonte: Lima (2018)

\subsection{REVESTIMENTO CONTRA CAVITAÇÃO}

Uma grande e importante aplicação dos compósitos está relacionada à cavitação. O fenômeno de cavitação ocorre pela ação da hélice na água, o que pode gerar bolhas de vapor na água e com isso danificar sua estrutura. O revestimento de compósito atua absorvendo o impacto das bolhas de vapor e com isso diminuindo a deterioração dos componentes, como ilustrado na figura 8.

Figura 8 - Proteção do substrato contra a cavitação
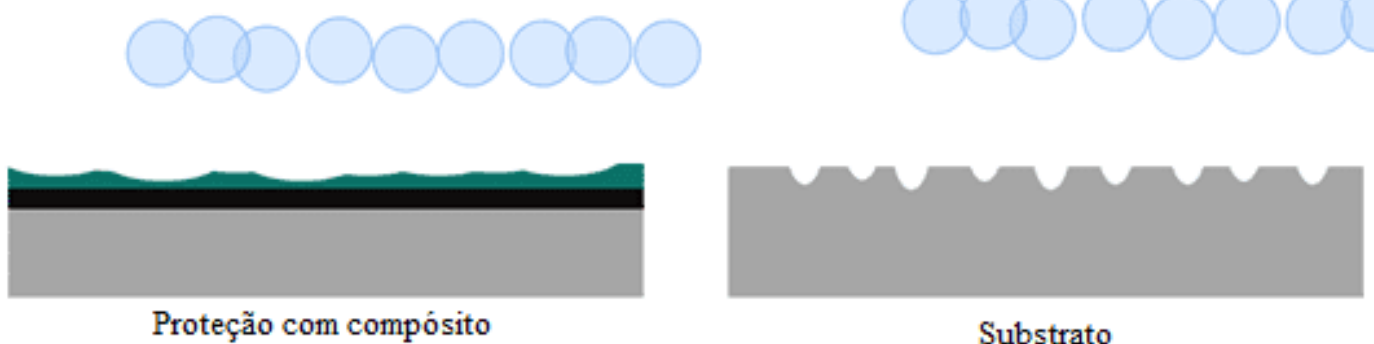

Substrato

Fonte: Lima (2018) 
A técnica pode ser usada em algumas estruturas do sistema propulsivo como propulsor, leme, tubulões, entre outros, como ilustrado na figura 9.

Figura 9 - Estruturas do sistema propulsivo protegidas com compósitos
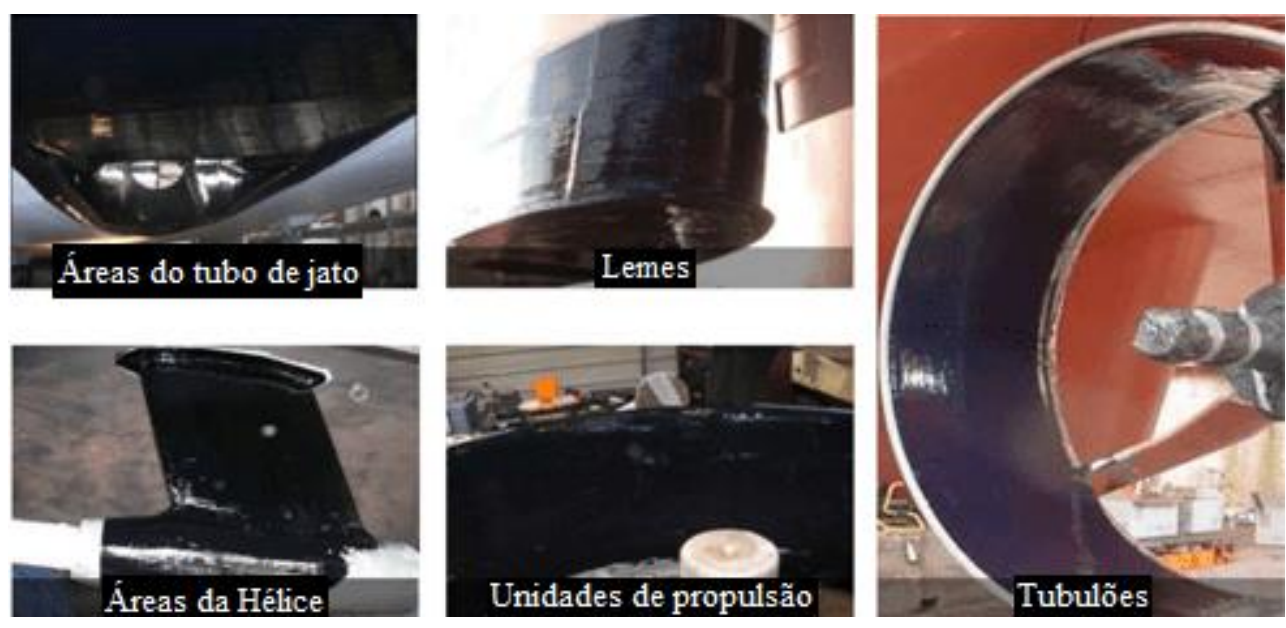

Fonte: Lima (2018)

\subsection{SELANTES EMERGENCIAIS}

Durante a operação podem ocorrer vazamentos nas tubulações, e, dessa forma, uma proposta de solução temporária seria o uso de compósitos como selantes emergenciais. Dependendo da qualidade do reparo, esses selantes de emergência podem ser temporários ou permanentes, como mostrado na figura 10.

Figura 10 - Selantes emergenciais

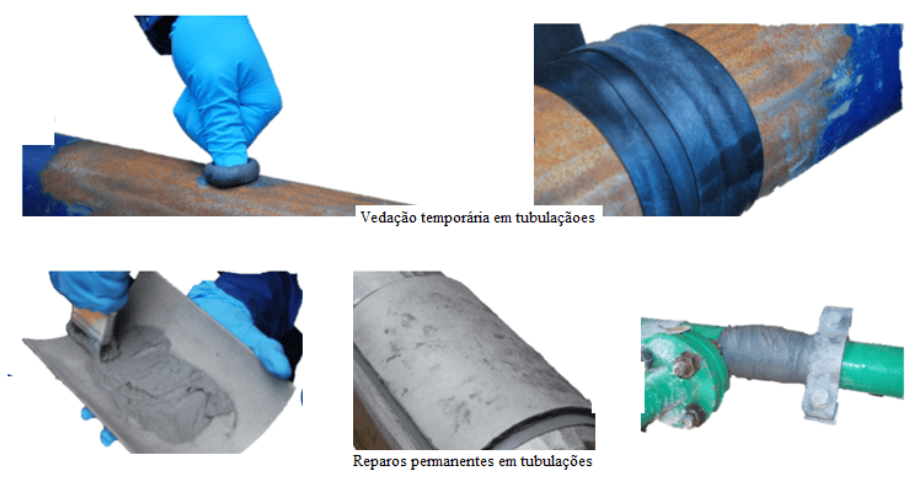

Fonte: Lima (2018) 


\section{DISCUSSÃO}

No que se refere aos reparos em trincas de estruturas de aço, o trabalho de Meniconini et al (2010) mostrou que o reparo de tanque de lastro em plataformas, mesmo em condições ambientais e de iluminação desfavoráveis, é de possível realização. Restauraram, então, a espessura mínima de projeto. A plataforma foi acompanhada e inspecionada e os resultados se mostraram satisfatórios. Perrut et al (2019) testaram, por sua vez, um novo tipo de preparação de superfície e obtiveram um resultado satisfatório, visto que o desempenho das juntas coladas pela máquina foi semelhante ao das juntas preparadas com jateamento. Um outro experimento foi feito para entender o efeito do ambiente, realizado por Arouche et al (2019). Os autores concluíram que a umidade não teve efeito relevante para o adesivo após 40 dias de imersão em água salgada.

A partir de 40 dias o processo de ganho de umidade acelera e a penetração de umidade acontece das beiradas para o centro. Outro estudo de Arouche et al (2018) apontou, também, um decréscimo na resistência do reparo enquanto imerso em água salgada. Colombi, Bassetti e Nussbaumer (2003), em seu experimento, detectaram a sensibilidade da espessura da camada adesiva para o nível de tensão do aço reforçado com compósito. O uso de reparos com compósitos para reforçar estruturas não trincadas também pôde ser notado. Bocciarelli et al (2009) usaram adesivos compostos de dupla face para estudar o desempenho de fadiga dos membros de aço em tensão. Lam et al (2007), em seu estudo, concluiu, com resultados de experimentação e com a análise numérica, que os valores de tensão de placas de aço fissuradas foram consideravelmente reduzidos com o reparo com compósito.

Com isso, a redução da intensidade do estresse resultaria em um aumento da vida em fadiga, como já havia sido demonstrado nos experimentos de Wang et al (2006). Os autores evidenciaram o crescimento de fadiga e trincas por tensão. Mostrou-se experimentalmente e analiticamente que o tempo de vida de fadiga dos substratos reparados aumenta à medida em que o número de camadas aumenta. Tavakkolizadeh e Saadatmanesh (2003), em seus experimentos, apontaram um aumento em três vezes na vida em fadiga se comparado com um aço que não foi 
reforçado. Em concordância, Huawen et al (2010) apontou o aumento de quatro vezes na vida em fadiga de placas de aço com defeito reforçadas. Tsouvalis, Mirisiotis e Dimou (2009), por sua vez, usaram o adesivo de carbono/epóxi em chapas de aço fissuradas que foram testadas em fadiga.

Os pesquisadores identificaram o aumento em duas vezes na vida em fadiga. Liu, AlMahaidi e Zhao (2009) realizaram testes de fadiga para placas de aço reforçado com adesivos compostos de fibra de carbono. O estudo concluiu, em concordância com os demais, que a vida em fadiga aumentou várias vezes. Já nos trabalhos sobre trincas em estruturas de alumínio, Grabovac e Whittaker (2009), de forma prática, analisaram a aplicação de reparos com fibra de carbono para conter a propagação de trincas por fadiga da superestrutura. Em 1993, os reparos com compósitos foram instalados na fragata HMS Sydney e depois desse tempo o navio operou por mais de 15 anos e passou por vários ciclos completos de manutenção sem apresentar problemas.

Seo e Lee (2002) analisaram o crescimento de trincas em placas de alumínio reparadas com compósito por meio da experimentação e modelagem numérica. Em sua conclusão, compararam o estresse calculado no experimento com o desenvolvido no método numérico. Wang et al (2006) analisaram o comportamento de trincas por fadiga em chapas de alumínio. Concluíram que o reparo com compósito aumenta significativamente a vida em fadiga da peça. Outros autores também analisaram de maneira numérica e experimental o crescimento de fissuras por fadiga em placas de alumínio. Identificaram que o reparo em painéis finos é mais eficiente que em painéis grossos (HOSSEINI-TOUDESHKY et al, 2007). Xiong e Shenoi (2008) analisaram o comportamento estático e de fadiga de diferentes espessuras de materiais de reparo em chapas de alumínio.

Foi confirmado que a espessura do adesivo tem grande influência na resistência e na fadiga da peça reparada. Khalili et al (2009) analisaram as chapas de alumínio com fissuras em sua fronteira reparadas com reparos de compósitos unilaterais. Afirmaram que reparos de carbono são mais eficazes no que diz respeito a placas rachadas quando comparadas as fibra de vidro. Com trabalhos referentes a reparo de corrosão em tubulações, Fujiyama e Bastian (2007), por sua vez, a partir de experimentos, 
observaram que a absorção de óleo nas tubulações pelo compósito foi pequena e gerou uma pequena degradação do material, e, ainda, apontaram que esse valor de absorção pequeno se deve ao fato de a molécula de óleo ser maior que a molécula de água.

Também Fujiyama e Bastian (2008), em outro estudo, mostraram que em tubulações a espessura da camada de reparo necessária para reparar tubulações de aço depende tanto da resistência do material composto quanto de uma menor a resistência do material, sendo necessária uma maior espessura da camada. CostaMattos et al (2009), em seu experimento, constataram que o requerimento principal quando se trata de corrigir danos de corrosão em tubulações acarretaria a cura rápida e alta distorção de calor temperatura. Os mesmos autores detectaram que os reforços de fibra de vidro em tubulações danificadas por corrosão revelaram que a tensão última depende fortemente da variação da temperatura, enquanto as propriedades plásticas não são afetadas.

\section{CONSIDERAÇÕES FINAIS}

Neste trabalho, foram apresentados os métodos mais usados e aplicados de reparo com compósitos na indústria naval e offshore. Realizou-se, também, uma revisão sobre o que tem sido recomendado no que tange a utilização desses reparos. Diversos artigos que dispõem sobre os três tipos mais importantes de reparos foram analisados: são eles reparo de trinca em estruturas de aço, reparo de trinca em estruturas de alumínio e reparo de tubulações danificadas por corrosão. A partir de uma análise dos resultados dos artigos, foi possível concluir que o reparo com compósito, quando comparado ao reparo tradicional, possui várias vantagens, como a não necessidade de aporte de calor, o que aumenta a segurança e diminui perdas na produção, além de um menor custo de realização.

Os reparos podem ser feitos "in situ", e, além disso, podem aumentar a resistência mecânica e outras propriedades da estrutura. Em contramão a isso, ainda não foram realizados experimentos suficientes que comprovem a confiabilidade dos reparos à longo prazo. Dessa forma, as classificadoras ainda não recomendam o uso deste tipo 
de reparo em estruturas críticas. Nessas situações, o reparo com solda ainda é a única opção disponível. Muitos artigos já foram e estão sendo publicados sobre o tema, e, por outro lado, muitos experimentos têm sido feitos no sentido de poder, num futuro, essa tecnologia, ser amplamente usada na indústria naval e offshore. Tudo indica que essa tecnologia tem sido cada vez mais utilizada, o que faz com que ela sempre se aperfeiçoe.

\section{REFERÊNCIAS}

ALVES, R. da. S. Reparos a frio em embarcações metálicas. 2018. 57f. Projeto de Graduação (Graduação em Engenharia) - Universidade Federal do Rio de Janeiro, Rio de Janeiro, 2018.

AROUCHE, M. M. et al. Effect of moisture on the adhesion of CFRP-to-steel bonded joints using peel tests. Journal of the Brazilian Society of Mechanical Sciences and Engineering, v. 40, n. 1, p. 10, 2018.

AROUCHE, M. M. et al. Interlaminar adhesion assessment of carbon-epoxy laminates under salt water ageing using peel tests. Proceedings of the Institution of Mechanical Engineers, Part L: Journal of Materials: Design and Applications, v. 233, n. 8, p. 1555-1563, 2019.

BARROS, S. de. et al. Experimental analysis of metal-composite repair of floating offshore units (FPSO). The Journal of Adhesion, v. 93, n. 1-2, p. 147-158, 2017.

BOCCIARELLI, M. et al. Fatigue performance of tensile steel members strengthened with CFRP plates. Composite Structures, v. 87, n. 4, p. 334-343, 2009.

COLOMBI, P.; BASSETTI, A.; NUSSBAUMER, A. Analysis of cracked steel members reinforced by pre-stress composite patch. Fatigue \& Fracture of Engineering Materials \& Structures, v. 26, n. 1, p. 59-66, 2003. 
COSTA-MATTOS, H. S. et al. An alternative methodology to repair localized corrosion damage in metallic pipelines with epoxy resins. Materials \& Design, v. 30, n. 9, p. 3581-3591, 2009.

COSTA-MATTOS, H. S. et al. Analysis of a glass fibre reinforced polyurethane composite repair system for corroded pipelines at elevated temperatures. Composite Structures, v. 114, p. 117-123, 2014.

ECHTERMEYER, A. T. et al. Bonded patch repairs for metallic structures-a new recommended practice. Journal of Reinforced Plastics and Composites, v. 33, n. 6, p. 579-585, 2014.

FUJIYAMA, R. T.; BASTIAN, F. L. Composite Material of Polyester Matrix and Fiberglass: Petroleum Aging. SAE Technical Paper, 2007.

FUJIYAMA, R. T.; BASTIAN, F. L. Composites Materials Used in Pipeline Repairs. SAE Technical Paper, 2008.

FREIRE, E.; MONTEIRO, E. E. C; CYRINO, J. C. R. Propriedades mecânicas de compósitos de polipropileno com fibra de vidro. Polímeros: Ciência e Tecnologia, v. 4, n. 3, p. 25-32, 2013.

GRABOVAC, I.; WHITTAKER, D. Application of bonded composites in the repair of ships structures-A 15-year service experience. Composites Part A: applied science and manufacturing, v. 40, n. 9, p. 1381-1398, 2009.

HOSSEINI-TOUDESHKY, $\mathrm{H}$. et al. Numerical and experimental fatigue crack growth analysis in mode-I for repaired aluminum panels using composite material. Composites Part A: applied science and manufacturing, v. 38, n. 4, p. 1141-1148, 2007.

HUAWEN, Y. et al. Fatigue performance of tension steel plates strengthened with prestressed CFRP laminates. Journal of Composites for Construction, v. 14, n. 5, p. 609-615, 2010. 
KHALILI, S. M. R. et al. An experimental study on the Charpy impact response of cracked aluminum plates repaired with GFRP or CFRP composite patches. Composite Structures, v. 89, n. 2, p. 270-274, 2009.

KHALILI, S. M. R.; SHIRAVI, M.; NOORAMIN, A. S. Mechanical behavior of notched plate repaired with polymer composite and smart patches-experimental study. Journal of reinforced plastics and composites, v. 29, n. 19, p. 3021-3037, 2010.

LAM, A. C. C et al. Repair of steel structures by bonded carbon fibre reinforced polymer patching: experimental and numerical study of carbon fibre reinforced polymer-steel double-lap joints under tensile loading. Canadian Journal of Civil Engineering, v. 34, n. 12, p. 1542-1553, 2007.

LIU, H.; AL-MAHAIDI, R.; ZHAO, X-L. Experimental study of fatigue crack growth behaviour in adhesively reinforced steel structures. Composite Structures, v. 90, n. 1, p. 12-20, 2009.

MENICONI, L. C. M. et al. Structural repair at a production platform by means of a composite material patch. In: Offshore technology conference, 2010.

MENICONI, L. C. M.; LANA, L. D. M.; MORIKAWA, S. R. K. Experimental fatigue and aging evaluation of the composite patch repair of a metallic ship hull. Applied Adhesion Science, v. 2, n. 1, p. 27, 2014.

MOURITZ, A. P开. et al. Review of advanced composite structures for naval ships and submarines. Composite structures, v. 53, n. 1, p. 21-42, 2001.

PERRUT, V. A. et al. Fatigue and quasi-static analysis of a new type of surface preparation used for the CFRP repair of steel offshore structures. The Journal of Adhesion, v. 95, n. 9, p. 849-873, 2019.

SEO, D-C; LEE, J-J. Fatigue crack growth behavior of cracked aluminum plate repaired with composite patch. Composite Structures, v. 57, n. 1-4, p. 323-330, 2002. 
TAVAKKOLIZADEH, M.; SAADATMANESH, $H$. Fatigue strength of steel girders strengthened with carbon fiber reinforced polymer patch. Journal of structural engineering, v. 129, n. 2, p. 186-196, 2003.

TSOUVALIS, N. G.; MIRISIOTIS, L. S.; DIMOU, D. N. Experimental and numerical study of the fatigue behaviour of composite patch reinforced cracked steel plates. International journal of fatigue, v. 31, n. 10, p. 1613-1627, 2009.

WANG, Q. Y. et al. Fatigue crack growth of bonded composite repairs in gigacycle regime. International journal of fatigue, v. 28, n. 10, p. 1197-1201, 2006.

XIONG, J. J.; SHENOI, R. A. Integrated experimental screening of bonded composites patch repair schemes to notched aluminum-alloy panels based on static and fatigue strength concepts. Composite Structures, v. 83, n. 3, p. 266-272, 2008.

Enviado: Abril, 2020.

Aprovado: Maio, 2020. 